\title{
БЛУМО-ПОДОБНЫЙ СИНДРОМ. КЛИНИЧЕСКИЙ СЛУЧАЙ
}

\section{${ }^{1,2}$ Кострова И.Б., ${ }^{1,2}$ Алиомарова П.М., ${ }^{2}$ Джамолодинова Э.М., ${ }^{3}$ Гончарова Н.А., ${ }^{2}$ Солтаханова А.Э., ${ }^{2}$ Солтаханов Э.М. \\ ${ }^{1}$ ГБУ ДРКБ им Н.М.Кураева МЗ РД}

${ }^{2}$ ФББОУ ВО «Дагестанский государственный медицинский университет» Минздрава России , г. Махачкала

${ }^{3}$ ФГБУ НМИЦ эндокринологии Минздрава России

Синдром Блума (СБ) - редкое наследственное аутосомно-рецессивное заболевание, вызванное мутацией гена BLM, характеризующееся низкорослостью, ослабленным иммунитетом, повышенной чувствительностью к солнечному свету, дистрофическими изменениями кожи. [1,2]. Второе название данного заболевания - «телеангиэктатическая врожденная эритема с задержкой роста». Этот синдром впервые был описан в 1954 г. Дэвидом Блумом у нескольких пациентов с телеангиэктатической эритемой на лице и карликовостью. [1]. Истинная частота встречаемости данного синдрома неизвестна, но в еврейском населении Ашкенази она оценена приблизительно в 1/48.000 новорожденных. [3]. С 2009г ведется Регистр Синдрома Блума (BSR). Общее количество пациентов менее 300. Из зарегистрированных пациентов $75.2 \%$ были не являются евреями. [4]. BLM кодирует 1417 аминокислот, которые закодированы в синтезе белка в ядерной матрице растущих клеток, которая является членом семьи RecQ геликаз. Этот белок играет центральную роль в рекомбинации и репарации ДНК. BMLмутации таким образом заканчиваются дефектами в репарации ДНК и геномной неустойчивостью в соматических клетках, предрасполагая пациентов к развитию различных онкологических заболеваний, которые являются основной причиной смерти у данных пациентов. Нет описанных пациентов старше 50 лет. У людей с синдромом Блума в 150-300 раз выше риск развития онкологии, чем в общей популяции. Новообразования характерные для СБ представлены лейкозами, лимфомами, раком кожи и молочных желез, колоректальным раком. Различные типы лейкозов развиваются в среднем в возрасте 22 лет. [5] . Диагностически отличительной особенностью синдрома Блума является наличие повышенных обменов сестринских хроматид (SCE) при цитогенетическом тестировании. Описаны фенотипически схожие случаи низкорослости с микроцефалией, но без телеангиэктатической эритемы. При молекулярно-генетическом исследовании (секвенированию по Сенгеру) у таких пациентов определены мутации гена ТОРЗА. У данных пациентов не обнаружены онкологические заболевания. Возможно это объясняется тем, что злокачественные опухоли при синдроме Блума обычно проявляется в раннем зрелом возрасте, а возраст наблюдаемых детей с синдромом ТОРЗА еще не достиг критического. В связи с этим мутации ТОРЗА могут также представлять собой повышенный риск развития злокачественных опухолей.

\section{Клинический случай из практики:}

Блума подобный синдром ТОР3А

В отделение эндокринологии ДРКБ поступил ребёнок 1год 6мес с жалобами на задержку физического развития.

Из анамнеза жизни и заболевания известно, что ребёнок от 4 беременности и 2 родов. 1 беременность - замершая на 11 неделе внутриутробного развития. 2 беременность - старший ребенок (сибс) с синдромальной патологией - «Синдром Блума». В 2года выставлен диагноз Дилятационная кардиомиопатия. Умер в 2 года 9 мес от нарастания сердечной недостаточности. Вскрытие не проводилось. 3 беременность - замершая на 8 неделе беременности. 4 беременность - Пробанд: 
беременность протекала благополучно до 23 недель. Далее на 28-30 неделе выявлена задержка внутриутробного развития-до гипотрофии 3 степени. Роды в срок, ПКС. Вес/рост при рождении1740кг/45см. По шкале APGAR 5-6 б. Выхаживался в кювезе, был переведен в OПН. Выписан на 27 сутки жизни. Находился на ИВ. С рождения задержка физического развития, черепно-лицевые дисморфии. Профилактические прививки не получал - мед.отвод. Инфекционные заболевания не переносил. Аллергия на белок коровьего молока.

Неврологический статус: психомоторное развитие соответствует возрасту. Отмечается лепет, взгляд фиксирует, слышит. Мышечный тонус и сухожильные рефлексы без патологических проявлений. Ползает с 8 мес, ходит с 1г 3 месяцев. Была травма головы (лобные отделы) с потерей сознания. В последующем были 2 травмы без рвоты и потерей сознания.

\section{Эндокринологический статус:}

Возраст- 1год 6 месяцев. Рост-70см, $\quad$ SDS роста $=-4,0$. Вес- 5кг. $\quad$ SDS веса=-4,95. ИМТ- 10,2 кг/м2. SDS ИМТ= -9,9. Костный возраст по атласу КВ соответствует 6 месяцам. Щитовидная железа не увеличена пальпаторно. Половое развитие по Таннеру 1 (G1P1),объем яичек справа и слева 2мл. Рост отца $=171 \mathrm{~cm}$. Рост матери $=162 \mathrm{~cm}$. Брак родителей родственный (муж и жена друг другу двоюродные тетя и племянник). Характерные стигмы дизэмбриогенеза: пренатальная задержка развития - низкая масса тела при рождении, низкий рост с пропорциональным строением тела, микроцефалия, узкое лицо, большой нос, оттопыренные ушные раковины. Светочувствительной телеангиэктатической эритемы в виде бабочки у ребенка нет.
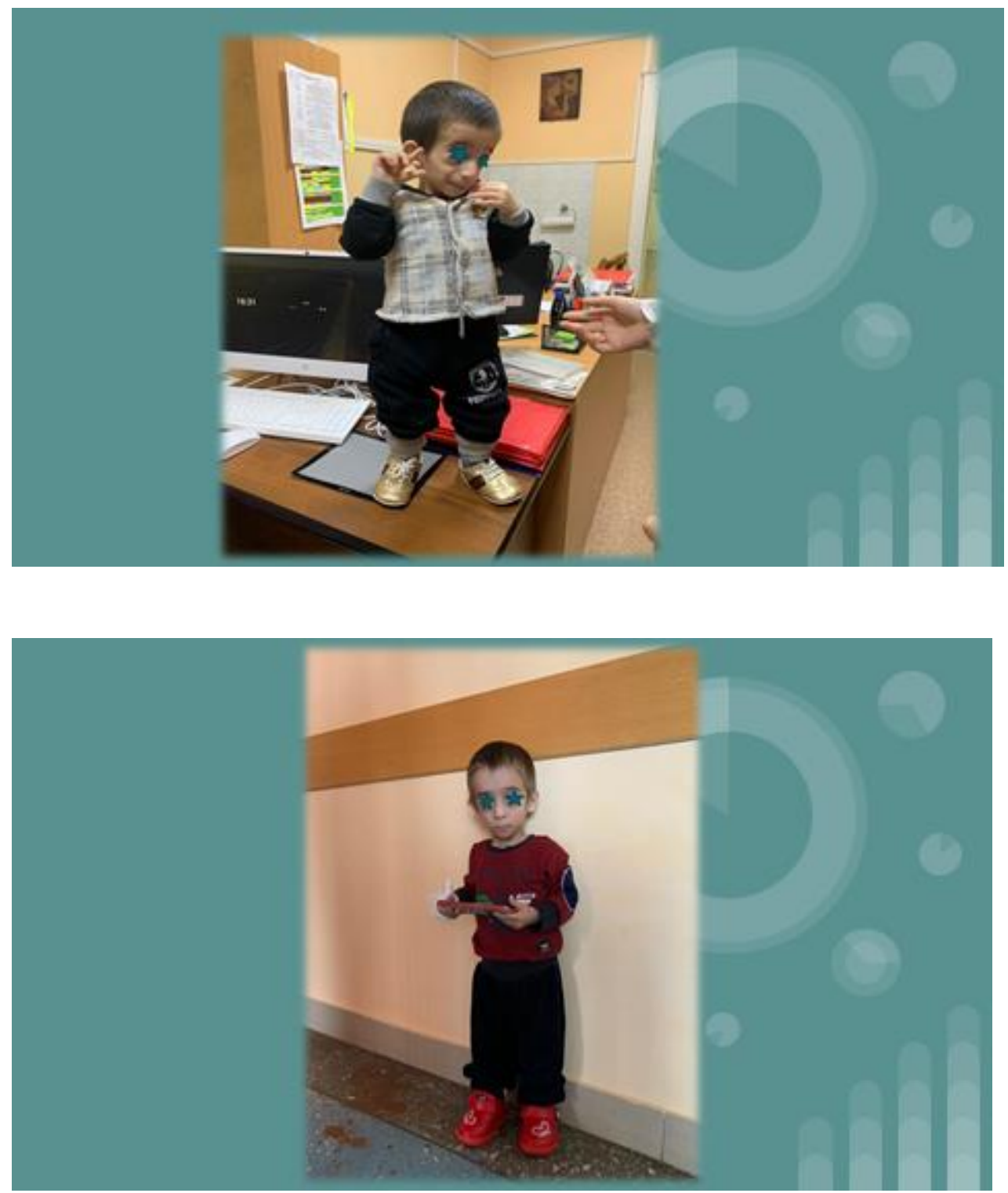
В данном обзоре клинического случая хочется уделить большее внимание Блумо-подобному нарушению, отличным незначительно фенотипически и генетически. Из зарубежных исследований [6] можно сделать вывод о том, что в отличие от синдрома Блума, Блума-подобные нарушения имеют клинические признаки, соответствующие митохондриальной дисфункции, одним из проявлений которого явилась дилатационная кардиомиопатия.

На генетическом уровне это представлено биаллельными мутациями в гене ТОРЗА, кодирующем фермент топоизомеразу III альфа цитогенетическое тестирование приводящий к развитию Блумоподобного синдрома. Считается, что синдром Блума возникает из-за мутаций в гене BLM. Мутации в генах BLM и TOP3A запускают похожие патогенетические механизмы. В результате неправильной работы комплекса BLM-TOPIII $\alpha$-RMI1-RMI2 в клетке формируются ультратонкие митотические мостики и микроядра, что, в свою очередь, ведет к неустойчивости генома и снижению жизнеспособности клеток в ходе развития (начиная с пренатального периода). Подобные отклонения и являются причиной карликовости, микроцефалии.

\section{Молекулярный анализ:}

Мутация, вызывающая синдром Блума , наблюдается в обоих аллелях гена BLM, унаследованного от обоих родителей. Нашему больному было проведено полное секвенирование экзома ( в ЭНЦ 09.12.2019г). Результаты: Проведен поиск изменений нуклеотидной последовательности в генах, ассоциированных с низкорослостью и задержкой внутриутробного развития.

В гене TOP3A( NM 004618) выявлен вариант: c.2264 2265delGGinsA. Не описан. Патогенный. Мутация в гене TOP3A описаны при синдроме MGRISCE2 (Микроцефалия,задержка роста и ускоренный обмен с сестринской хроматидой 2 типа).

\section{Лечение:}

У данных пациентов нет определенного лечения, но есть общие рекомендации: 1- избегать чрезмерной инсоляции

2 - Гормон роста не назначается по причине его неэффективности и высокого риска онкологических заболеваний.

3- При низких уровнях иммуноглобулинов в сыворотки крови назначается терапия иммуноглобулинами.

4- В лечение рака у больных с данным синдромом имелись трудности с химиотерапией.

Стандартная химиотерапия заканчивалась значительной токсичностью и тяжелыми иммунодефицитами у данных больных. Требовалось снижение дозы и циклов химиотерапии.

В дальнейшем данные пациенты находятся на учете у эндокринолога, дерматолога, онколога, педиатра и инфекциониста. Родителям для дальнейшего планирования детей рекомендовано проведение ЭКО с предимплантационной диагностикой (ПДГ эмбриона).

В табл 1. представлены особенности характерные для различных вариантов синдромальной низкорослости имеющих сходства с синдромом Блума.

Синдромы

Блум-подобный синдром

Блума

Секкеля 


\section{Ниймеган}

Фенотип

Пренатальная, постнатальная задержка роста ,микроцефалия, узкое лицо, экзофтальм, клювовидный нос, кардиомиопатия, иммунодефицит,

Пренатальная, постнатальная задержка роста , микроцефалия, узкое лицо, экзофтальм, клювовидный нос, деформация грудной клетки, гипертрихоз, пятна цвета «кофе с молоком», легочные инфекции ,телеангиэктазия, склоность к диабету, злокачественные новообразования

Пренатальная, постнатальная задержка роста , микроцефалия, узкое лицо, экзофтальм, клювовидный нос, задержка психоречевого развития, злокачественные новообразования.

Пренатальная, постнатальная задержка роста , микроцефалия, узкое лицо, экзофтальм, клювовидный нос, высокое небо ,иммунодефицит, кожная пигментация, легочные инфекции, легочные инфекции, лимфома

Результаты молекулярно-генетических исследований

Мутация в гене ТОР3А

Мутация в гене BLM

Мутация в гене

ATR

Мутация в гене

NBS1

Тип наследования

Аутосомно-рецессивный

Аутосомно-рецессивный

Аутосомно-рецессивный

Аутосомно-рецессивный

Резюме: учитывая данные клинического и молекулярно-генетического исследования был сделан вывод, что у наблюдаемого нами пациента имеет место Блумо-подобный синдром, имеющий схожее с Синдромом Блума клиническое течение и терапию, но отличающееся генетически. Ведение таких пациентов проводится мультидисциплинарной командой. [7, 8].

Список литературы:

1. Bloom D. Congenital telangiectatic erythema resembling lupus erythematosus in dwarfs; probably a syndrome entity. AMA Am J Dis Child. 1954 Dec. 88(6):754-8

2. Masmoudi A, Marrakchi S, Kamoun H, Chaaben H, Ben Salah G, Ben Salah R, et al. Clinical and laboratory findings in 8 patients with Bloom's syndrome. J Dermatol Case Rep. 2012 Mar 27. 6 (1):2933. DOI: http://dx.doi.org/10.3315/jdcr.2012.1086

3. Risch N, Tang H, Katzenstein H, Ekstein J. Geographic distribution of disease mutations in the Ashkenazi Jewish population supports genetic drift over selection. Am J Hum Genet. 2003 Apr. 72(4):812-22.

4. Weill Cornell Medical College, Bloom's Syndrome Registry. A Concise Clinical Description of Bloom's Syndrome. Available at http://weill.cornell.edu/bsr/clinical_description/. 2009; Accessed: February 16, 2017.

5. Amira M Elbendary, Dirk M Elston, Bloom Syndrome (Congenital Telangiectatic Erythema)(medscape.com); https://emedicine.medscape.com/article/1110271

6. Martin, C.-A., Sarlos, K., Logan, C. V., Thakur, R. S., Parry, D. A., Bizard, A. H., Leitch, A., Cleal, L., Ali, N. S., Al-Owain, M. A., Allen, W., Altmuller, J., and 40 others. Mutations in TOP3A cause a Bloom syndrome-like disorder. Am. J. Hum. Genet. 103: 221-231, 2018. Note: Erratum: Am. J. Hum. 
Genet. 103: 456 only, 2018. [PubMed: 30057030, related citations] [Full Text] https://doi.org/10.1016/j.ajhg.2018.07.001.

7. Cunniff C, Djavid AR, Carrubba S, Cohen B, Ellis NA, Levy CF, et al. Health supervision for people with Bloom syndrome. Am J Med Genet A. 2018 Sep. 176 (9):1872-1881 DOI: 10.1002/ajmg.a.40374

8. Fein Levy C, Presswala LS, Slomovic A,Stiefel J, Schulman-Rosenbaum R. Multidisciplinary management of endocrinopathies and treatment-related toxicities in patients with Bloom syndrome and cancer. Pediatr Blood Cancer. 2020;e28815. https://doi.org/10.1002/pbc.28815 